\title{
O Ensino de Sociologia como Problema Epistemológico e Sociológico
}

\author{
Juarez Lopes de Carvalho Filho' \\ 'Universidade Federal do Maranhão (UFMA), São Luís/MA - Brasil
}

RESUMO - O Ensino de Sociologia como Problema Epistemológico e Sociológico. Este artigo propõe discutir o ensino de sociologia como problema epistemológico e sociológico, atentando para uma comparação entre a França e o Brasil. Analisa o processo de constituição da sociologia como ciência e como disciplina, assim como a produção e a circulação do saber sociológico. Postula-se que a falta de legitimidade da disciplina e do seu reconhecimento social encontra-se no antigo problema da definição dos seus objetivos (função social) e do seu lugar na formação social e educacional do indivíduo e de sua cidadania crítica. Desse modo, o ensino de sociologia se revela como um problema social e político.

Palavras-chave: Ensino de Sociologia. Saber Sociológico. Constituição da Ciência. Constituição da Disciplina.

ABSTRACT - The Teaching of Sociology as an Epistemological and Sociological Problem. This article aims to discuss the teaching of sociology as epistemological and sociological problem, noting a comparison between France and Brazil. It analyzes the process of constitution of sociology as a science and as a discipline, as well as the production and circulation of sociological knowledge. It is postulated that the lack of legitimacy of the discipline and its social recognition is the old problem of defining its goals (social function) and its place in the social formation and education of the individual and critical citizenship. In fact, the teaching of sociology reveals itself as a social and political problem.

Keywords: Teaching Sociology. Sociological Knowledge. Constitution of Science. Constitution of Discipline.

Educação \& Realidade, Porto Alegre, v. 39, n. 1, p. 59-80, jan./mar. 2014.

Disponível em: <http://www.ufrgs.br/edu_realidade> 
O Ensino de Sociologia como Problema Epistemológico e Sociológico

\section{Introdução}

O presente artigo propõe uma análise epistemológica e históricosocial do processo de institucionalização da sociologia no nível médio, atentando para possíveis comparações entre o caso no Brasil e na França. Busca-se construir, ainda que em estado provisório, um quadro que ofereça elementos comparativos a fim de determinar as proximidades e os distanciamentos entre os dois países, contribuindo para uma melhor compreensão dos jeux et enjeux que se encontram por trás do processo de construção social do conhecimento sociológico (formação social da disciplina), do processo de institucionalização da sociologia no meio acadêmico (nível médio e superior) e do problema do seu ensino.

Colocar o problema do ensino da sociologia no Ensino Médio, seja no Brasil ou na França, é colocar o problema da construção e da transmissão do saber sociológico, o que supõe um recuo histórico do processo de formação da sociologia como ciência e como disciplina. Nesse sentido, a questão posta é sobre o processo de institucionalização, não somente legal - a obrigatoriedade da disciplina no currículo da educação básica -, mas também do seu reconhecimento social enquanto disciplina, por parte dos agentes sociais da educação: professores, gestores, técnicos, alunos. A maneira como se percebe a construção do conhecimento sociológico e sua transmissão (seu ensino) permite encontrar outros objetos de estudo: a formação da sociologia; a formação de professores, os modos de recepção da disciplina (tanto por parte dos professores, como por parte dos alunos da educação básica); as estratégias do método de ensino-aprendizagem etc. Nessa perspectiva, construir um discurso científico sobre o ensino de sociologia no nível médio significa fazer uma sociologia da sociologia ou uma sociologia reflexiva, como propunha Pierre Bourdieu desde muito cedo. Isso exige desvelar as condições objetivas de elaboração, de apropriações, dos modos de transmissão e as condições de recepção do conhecimento sociológico.

A questão da legitimidade e do reconhecimento social da sociologia do ponto de vista científico e institucional, assim como seu processo de profissionalização e sua inserção no mercado de trabalho e, especialmente, do seu ensino, só pode ser examinada numa perspectiva da história da própria sociologia.

Busca-se aqui, num primeiro momento, levantar problemas sobre as questões enfrentadas pela sociologia e os sociólogos, no que diz respeito à sua utilidade, quer dizer, à sua função social. Essa questão colocada desde os primórdios da sociologia persegue-a permanentemente. O desencadeamento dessa reflexão evidenciará questões ligadas ao processo de institucionalização da disciplina no interior do universo acadêmico e suas práticas no interior dos institutos de pesquisa. Num segundo momento, discutem-se as tentativas de profissionalização da sociologia na França; certamente esse caso emblemático oferece elementos para analisar o problema vivido de forma mais intensa no Brasil 
nos últimos anos, consequência da introdução da disciplina no currículo da educação básica. Pode-se perceber um lugar comum do problema vivido entre os dois casos, a saber: o processo de constituição da ciência antecede o da disciplina. No entanto a profissionalização, o reconhecimento social do seu status de ciência e disciplina é o resultado de um longo processo de luta e concorrência no campo científico e acadêmico, cuja consolidação supõe a instalação de instituições de ensino e pesquisa - dimensões que, no caso da França, estão muito mais imbricadas do que no Brasil.

Será visto ainda que, nos dois casos, o ensino da sociologia se revela como problema social e político, na medida em que a conjuntura social na qual se encontram os professores e os alunos exerce uma influência direta sobre o ensino, de certa forma, independentemente do programa (Chatel; Grosse, 2002). Postula-se que a falta de legitimidade da disciplina, não mais hoje do ponto de vista legal, mas do reconhecimento social, encontra-se no antigo problema de definição dos objetivos e do lugar social da sociologia na formação social e educacional do indivíduo, cidadão crítico.

\section{Da Utilidade da Sociologia}

É muito comum colocar-se a questão - por demais banal - a respeito da importância da sociologia, não somente no tocante ao Ensino Médio, mas também sobre a utilidade da sociologia em geral. Aliás, a mesma pergunta se coloca desde os tempos mais clássicos da formação da própria sociologia como ciência: para que serve? Revisitando a literatura da história da construção da sociologia, podem-se encontrar várias tentativas de se responder a tal questionamento, de Durkheim a Bourdieu, passando por Weber e Wright Mills. É possível afirmar, como François Dubet (2011), que não há sociólogo que não pense como Durkheim, que a sociologia não valeria uma hora de esforço se não se acreditasse na sua utilidade. Contudo a crença na utilidade da sociologia advém não somente de razões intelectuais, mas em função da própria transformação da sociedade moderna e a necessidade de ela construir uma representação social do mundo social. Dubet (2011) chama atenção para a necessidade de uma precaução no que diz respeito à palavra utilidade, pois, no seu sentido estrito, a sociologia, como a ciência, visa primeiramente a produzir conhecimentos, e, assim sendo, ela não se submeteria a nenhum princípio de utilidade. Seria então, segundo ele, necessário falar de utilidade num sentido mais amplo: qual o papel da sociologia na vida social e qual sua vocação? O autor explica que, quando a sociedade deixou de ser vista como um projeto divino ou como produto transparente da vontade dos homens em estabelecer livre e racionalmente um contrato social, segundo o projeto iluminista, esses postulados deixaram de servir para explicar como se formam e se transformam as sociedades; a partir do momento em que não se crê mais no mesmo deus, ou em nenhum; quando o Estado soberano e 
O Ensino de Sociologia como Problema Epistemológico e Sociológico

as leis não organizam mais a totalidade da vida social e a mudança se tornou uma regra, surge a necessidade e a utilidade da sociologia. No entanto, de maneira elementar, a sociologia sublinha sempre uma distância entre as representações e as realidades, entre os princípios mais elevados e os fatos mais banais. A própria objetivação dessa distância apresenta-se como uma utilidade (Dubet, 2011).

Segundo Bernard Lahire (2002), no centro dessa questão sobre a utilidade da sociologia, encontram-se as seguintes preocupações: que tipo de inserção profissional pode-se esperar com tal diploma universitário de Ciências Sociais? Por quê? Com qual interesse e com quais objetivos devemos fazer a análise do mundo social? Ou qual papel a sociologia exerce no curso da história e no bojo das transformações sociais? Para o autor, essas questões se justificam por duas razões: em primeiro lugar, porque temos uma disciplina academicamente e cientificamente menos legítima do que as outras (a física, a química, a matemática, a neurociência etc.). Num segundo momento, porque a sociologia é pressionada, por seu próprio objeto, a encontrar, mais do que as outras ciências, demandas de justificação ou de questionamento de seus resultados. No que concerne a esse segundo ponto, pelo fato de o sociólogo voltar seu olhar para sua própria sociedade tomada como objeto de sua investigação, pelo fato de a sociologia, desde sua formação, preencher uma função crítica, e, por fim, porque seus resultados são legíveis pelos seus próprios objetos de pesquisas (os agentes sociais), a sociologia é uma das raras ciências que é obrigada a desfazer mal-entendidos, de passar seu tempo a explicar e a justificar sua démarche do que a fornecer seus resultados e análises (Lahire, 2002). Embora Lahire reconheça a permanente luta da sociologia para explicar seu caráter científico, ele acentua que

[...] o sentimento da utilidade ou de inutilidade de um saber provém frequentemente menos da natureza desse saber do que de seu valor acadêmico e extra-acadêmico (fraco ou forte prestígio dos estudos, fraco ou forte inserção no mercado profissional, pequena reputação do emprego ocupado) (Lahire, 2002, p. 7) ${ }^{1}$.

Para ele, a alta legitimidade e o grande valor (econômico ou simbólico) que o mundo social atribui a certas atividades acabam por eliminar o sentido de qualquer interrogação sobre as razões fundamentais e as utilidades dessas últimas. ciologia

Nesse sentido, Bourdieu já chamava a atenção para o fato de a so-

[...] ter o triste privilégio de se confrontar incessantemente com a questão da sua cientificidade. É-se menos exigente para com a história ou a etnologia, sem falar da geografia, da filologia ou da arqueologia. Incessantemente interrogado, o sociólogo interroga-se incessantemente. O que faz com que se acredite num imperialismo sociológico: o 
que é esta ciência incipiente, balbuciante, que se permite submeter a exame as outras ciências! Estou a pensar, evidentemente, na sociologia da ciência. De fato, a sociologia não faz mais que pôr às outras ciências questões que lhe põe de maneira particularmente aguda. Se a sociologia é uma ciência crítica, talvez seja por estar em uma posição crítica (1984, p. 19).

Essa posição de Bourdieu, a respeito das constantes demandas de explicação e justificativa do caráter científico da sociologia, já era também observada por Durkheim. Desde seus primeiros anos de exercício na pratica docente, o sociólogo francês, encarregado de lecionar uma disciplina em via de constituição, enfrentou o problema da falta de legitimidade da sociologia tanto no campo científico quanto no campo acadêmico. A esse respeito, ele afirmava:

\begin{abstract}
Discutir para saber se uma ciência é possível e viável é sempre uma perda de tempo. No que se refere à sociologia a questão não é só desnecessária; ela é prejudicada. A sociologia existe; vive e progride; tem um objeto e um método; encerra uma variedade suficientemente grande de problemas para justificar desde já uma divisão do trabalho; suscitou trabalhos notáveis na França como no estrangeiro e sobretudo no estrangeiro; e por fim ela é chamada a prestar na ordem prática serviços incalculáveis (Durkheim, 1975, p. 189)2.
\end{abstract}

\title{
Processo de Profissionalização da Sociologia
}

A questão do processo de profissionalização da sociologia e do seu ensino deve ser estudada do ponto de vista da própria história da sociologia. Segundo Claude Dubar (2002), essa questão é inseparável da história da própria disciplina e notadamente do seu ensino, que na França começa a ser objeto de análises globais, no que diz respeito à periodização. Podemos citar, a título de exemplo, os estudos de Claude Dubar, Les Tentatives de Professionalisation des Études de Sociologie (2002); de Alain Chenu, Une Institution Sans Intension: la sociologie en France depuis l'après-guerre (2002); e de Sthéphane Beaud, La Sociologie Française au Milieu du Gué (2012). Esses estudos retomam alguns elementos característicos que revelam um longo processo de estruturação e constituição da sociologia como ciência legítima e como disciplina autônoma nos centros acadêmicos (universidades e escolas secundárias) e nos centros de pesquisa empírica.

Segundo Dubar (2002), podemos caracterizar essa periodização da seguinte forma: a primeira fundação da sociologia na França e o fracasso de sua institucionalização (1895-1945); a refundação da sociologia até a criação da licenciatura (1945-1958); e a institucionalização da disciplina na universidade e fora dela (1958-1976). Para Dubar, é ambíguo falar de profissionalização da sociologia, pelo fato de o próprio termo

Educação \& Realidade, Porto Alegre, v. 39, n. 1, p. 59-80, jan./mar. 2014. 
O Ensino de Sociologia como Problema Epistemológico e Sociológico

mudar de sentido no curso da história. Para este sociólogo, apesar da criação de diplomas profissionais de sociologia, não existe um diploma de sociólogo profissional, como existe para o demógrafo, o estatístico e o psicólogo. O autor arrisca mesmo a afirmar que a própria questão da introdução do ensino das Ciências Econômicas e Sociais (como é a nomenclatura na França) nos programas de liceus não foi um vetor de profissionalização de diplomas de sociologia, como é o caso já de muitos anos dos historiadores, geógrafos ou filósofos. Para o propósito deste artigo, é importante caracterizar aqui esses três períodos.

\section{A Fundação da Sociologia na França (1895-1945)}

Esse período é o de constituição da sociologia como ciência e uma disciplina científica sob a égide dos durkheimianos, no final do século XIX. Contava com intelectuais, filósofos, antropólogos, historiadores, economistas, empenhados na tentativa de dar à sociologia o status de ciência (Dubar, 2002). Entretanto, se de uma parte Durkheim estabelecia as propriedades da sociologia enquanto ciência, com seu objeto bem definido e as regras do método, distinguindo-se das ciências já consolidadas, como as ciências da natureza (química, biologia) e a psicologia, no campo acadêmico e intelectual, de outra parte, a consolidação do reconhecimento da legitimidade da sociologia enfrentava uma luta e concorrência pela apropriação do conhecimento sobre o mundo social. Além da refundação da metafísica, quer dizer da emergência do neotomismo francês, dirigido pela Igreja Católica e a colaboração de intelectuais (filósofos e escritores católicos) ${ }^{3}$, a escola de pensamento durkheimiana teve de enfrentar uma outra tentativa de profissionalização da sociologia, a saber, o movimento dirigido por René Worms que lançou a primeira Revue Internationale de Sociologie, em 1893, dois anos antes do primeiro número da revista durkheimiana, L’Année Sociologique (Dubar, 2002).

Outro marco desse período foi a criação, em 1900, da École des Hautes Études Sociales pelos durkheimianos, que se constituía em uma escola livre, mas sem muito futuro. Como observa Dubar (2002), a introdução da sociologia na universidade foi lenta e muito parcial. A cátedra de sociologia ocupada por Durkheim em Bordeaux chamava-se Pédagogie et Sciences Sociales, e a que ele ocupou na Sorbonne, em 1902, chamava-se Sciences de l'Éducation. Ela se tornaria Sociologie somente em 1913, e não continuou após sua morte, em 1917. Relembra Dubar (2002) que a cátedra que Maurice Halbwachs ocupara no Collège de France, em 1944, chamava-se Psychologie Collective.

Como podemos perceber, embora a sociologia seja uma ciência recente (fim do século XIX) e mais recente ainda a sua institucionalização como disciplina (meados do século XX), o processo histórico de sua institucionalização e tentativa de profissionalização datam da sua fundação. Isso dito, ainda não foi com Durkheim que a sociologia tornou- 
se uma disciplina universitária autônoma. Além disso, ela ficaria ainda na órbita da filosofia, pois somente em 1920 foi criado um Certificat de Morale et Sociologie. Neste ano, a sociologia foi introduzida nas escolas normais primárias, como desejava Durkheim, que já havia ligado de maneira estreita a sociologia e a educação, e havia vislumbrado um projeto científico da fundação da moral republicana, uma moral laica, agora desvinculada da moral cristã-católica. A sociologia deveria, segundo Durkheim, servir de instrumento de difusão da educação moral ${ }^{4}$.

Como observa Dubar (2002), o lugar da sociologia se encontrava, no ensino universitário, ao lado da moral, no interior do curso de filosofia, o que não implicava, evidentemente, nenhuma iniciação a um método de análise empírico e, a fortiori, nenhuma preparação a uma pesquisa de campo. Em 1924, no entanto, foi criado por um grupo de intelectuais o Institut Français de Sociologie, que durou até 1962. Este instituto, segundo Karady (1976 apud Dubar, 2002, p. 98), era concebido como "uma sociedade exclusivamente científica e fechada". Era um lugar de cientistas de todas as disciplinas que eles chamavam de Sciences Sociales, definidas como "ciência do homem vivendo em sociedade". Todavia, segundo Dubar (2002), esses eminentes intelectuais, especialistas da história antiga, da etnologia e da geografia, se recusaram a defender o ensino da sociologia nas escolas primárias, ameaçada e suprimida em 1934 pela direita; e se recusaram também a se engajar na criação de um ensino da sociologia no meio universitário e mesmo a escrever um manual de sociologia. A sequência do descrédito da sociologia na véspera da Segunda Guerra Mundial e no pós-guerra é conhecida. Segundo Alain Chenu (2002, p. 46),

[...] em 1945, a sociologia francesa está em baixa: nenhuma revista marcante, e havia número reduzido de posto universitário locado na órbita da filosofia, praticamente não existe pesquisa coletiva organizada (exceto sob a égide de uma equipe neoleplaysiana, benévola, constituída ao lado de Economia e Humanismo) ${ }^{5}$.

Do ponto de vista acadêmico, existiam somente três cátedras de sociologia na universidade (Paris, Bordeaux, Strasbourg), e seu ensino permanecia embutido no curso de filosofia. Do ponto de vista da pesquisa empírica, contrariamente a outros países (por exemplo, a sociologia americana, cujo departamento foi criado na Escola de Chicago em 1892), a sociologia empírica na França não conseguiu se construir, nem se impor, mesmo tendo sido um projeto dos durkheimianos (Dubar, 2002).

\section{A Refundação da Sociologia: institucionalização da sociologia empírica e a criação da licenciatura (1945-1958)}

Dois acontecimentos concorrem para a refundação da sociologia francesa: a instalação de institutos de pesquisa e a criação da licencia- 
O Ensino de Sociologia como Problema Epistemológico e Sociológico

tura em sociologia. Esse período se inaugura com a criação, em 1946, do Centre d'Études Sociologiques, no interior do Centre National de Recherches Scientifiques (CNRS). Como diz Chenu (2002, p. 46),

[...] um corpo de pesquisadores profissionais praticando uma sociologia empírica centrada sobre a observação das sociedades contemporâneas se coloca em prática na França por volta de 1950, no âmbito do CNRS. Essa geração pioneira, formada em perspectivas diversas, descobre o trabalho de campo.

É preciso lembrar que, após a Segunda Guerra Mundial, com a morte de Marcel Mauss, a sociologia durkheimiana entrou em declínio. Nesse processo de refundação da sociologia, na França, Georges Friedmann exerceu um papel determinante entre os anos 1948 e 1951, consagrando-se, juntamente com jovens pesquisadores, a vários domínios de investigação sociológica, como a escola, a cidade, o lazer, o sindicato, o trabalho etc. Mas, em efeito, a sociologia empírica reconstituiu-se em primeiro lugar em torno da Sociologia do Trabalho, representada notadamente por Georges Friedmann e Pierre Naville. Tratava-se, então, de um domínio socialmente importante, na França como em vários países da Europa: o crescimento do movimento operário, as preocupações ligadas à conquista da produtividade formaram um contexto favorável ao estudo das realidades do trabalho.

Outra iniciativa à pesquisa apareceu em 1947, no seio da VI seção da École Pratique des Hautes Études (EPHE) que se tornaria, a partir de 1968, a École des Hautes Études en Sciences Sociales (EHESS). Foi somente nessa época que se começou a falar de profissionalização da sociologia para designar essa nova disciplina, voltada para a compreensão do mundo contemporâneo e fundada na "utilidade das pesquisas de base empírica” (Heilbron,1986 apud Dubar, 2002, p. 100).

O outro acontecimento marcante desse período foi a criação, em 1958, da licenciatura em sociologia, sob os auspícios de Raymond Aron, eleito em 1957 para lecionar na Sorbonne. A grande novidade do momento era a autonomia da sociologia em relação à filosofia. A licenciatura em sociologia compreendia, inicialmente, quatro certificados: Sociologia Geral, Psicologia Social, Economia Política e uma opção a escolher, numa lista restrita (Demografia, História Econômica e Social). A partir daí, a licenciatura se espalhou por algumas grandes cidades, como Lyon, Nancy, Strasbourg, Lille, Bordeaux, Toulouse etc.

\section{Institucionalização da Disciplina na Universidade: 1958-1976}

A introdução da sociologia no meio universitário, notadamente com a criação de uma licenciatura, mesmo acompanhada de um terceiro ciclo (em 1962), nível de doutorado, não significou, segundo Dubar (2002), que uma formação profissional da sociologia existisse na universidade francesa. Verifica-se que "a licenciatura é um diploma engana- 
dor", uma vez que o ensino era unicamente teórico e enciclopédico, não existindo, então, uma formação voltada à pesquisa empírica (Heilbron, 1986, p. 71). Isso dito, assim como a de psicologia, a licenciatura em sociologia representava uma ambição para a disciplina, no que concerne à inserção no mercado de trabalho, sobre o exercício da atividade profissional fora do mundo universitário e dos organismos de pesquisa (Chenu, 2002). O crescimento econômico e as análises do sentido e do alcance das transformações sociais em curso na escala mundial deram lugar a enfrentamentos extremamente vivos, e cresceu o interesse pelas ciências sociais. No entanto a questão da qualificação profissional do diploma de sociologia foi colocada em 1965, por Jean-René Tréanton, no âmbito da Société Française de Sociologie, de um projeto de diploma d'expert sociologue, que também não teria sequência (Chenu, 2002; Heilbron, 1986).

Alain Touraine, que começou sua carreira de sociólogo como especialista do trabalho industrial no início dos anos 1960 e construiu um modelo teórico geral centrado na noção de "sociedade industrial" e de "sociedade pós-industrial”, propôs, em 1965 (Chenu, 2002), uma profissionalização da sociologia no mercado de trabalho, fora dos organismos de pesquisa e do meio universitário. Para Touraine (1965 apud Chenu, 2002, p. 49-50),

[...] a sociologia não pode se desenvolver se não se torna uma profissão, se representando um conjunto de conhecimentos criados, transmitidos e utilizados. Na França, o esforço principal foi consagrado ao desenvolvimento da pesquisa sociológica. Escolha razoável, mas que conduziria a consequências irracionais se acreditamos possível assegurar o progresso da pesquisa sem reforçar ao mesmo tempo o ensino e sem criar outros postos de trabalho que não sejam a pesquisa e o ensino.

É possível ainda se referir a dois colóquios, em 1965, que testemunharam o reconhecimento da sociologia da parte de notáveis funcionários da contabilidade nacional e do planejamento: um dirigido por Pierre Bourdieu e Alain Darbel (estatístico do INSEE que trabalhou com Pierre Bourdieu), que publicou Partage des Bénéfices, e outro, o primeiro organizado pela Société Française de Sociologie, J.-D. Reynaud, que publicou Tendences et Vonlontés de la Société Française (1966). Para concluir essa parte, é também emblemático que, no contexto de maio de 68, a palavra sociologia, que não era pronunciada fora dos espaços acadêmicos universitários, passou a ser usada numa linguagem comum; e sua popularização foi reforçada com sua introdução no ensino secundário. Como observa Chenu (2002, p. 50),

[...] o ensino secundário se abre às 'ciências econômicas e sociais', que acedem assim a um nível de reconhecimento outrora reservado às ciências e às humanidades clássicas. Sociologia e economia são dois componentes maiores des-

Educação \& Realidade, Porto Alegre, v. 39, n. 1, p. 59-80, jan./mar. 2014.

Disponível em: <http://www.ufrgs.br/edu_realidade> 
ses ensinamentos, que se caracterizam por uma abertura interdisciplinar. O termo de 'sociologia', diferentemente do termo 'economia', não aparece nem nos temas definindo as matérias dos programas de classes do segundo ano do liceu, nem nos programas dos concursos de recrutamento. As escolas normais superiores se dotaram de seções de SES (Sciences Économiques et Sociales) a partir de 1972 e a agrégation de sciences sociales foi criada em 1976.

Observa-se, assim, o longo processo de constituição, consolidação e institucionalização da sociologia como ciência e como disciplina. Processo feito de lutas, disputas, não somente pelo espaço social acadêmico-científico, mas também pela autoridade de falar com legitimidade do mundo social, num contexto seja de guerra ou de pós-guerra, ou de crescimento econômico e transformações sociais e políticas na escala mundial. Nos últimos anos, porém, pode-se dizer que se constituiu um vasto conjunto de instituições de ensino e de pesquisa por meio das quais a sociologia, na França, adquiriu um lugar social e acadêmico consolidado, apesar das constantes transformações. É evidente, no entanto, que certa legitimidade da sociologia, seja no campo científico, seja no campo acadêmico, encontre força na instalação das instituições de fomento à pesquisa e dos estabelecimentos de ensino das ciências sociais no nível superior.

\section{Em Busca de uma Função Social da Sociologia no Ensino Médio}

Algumas tentativas de justificar a utilidade da sociologia, ou seja, de definir sua função social ou de torná-la legítima cientificamente, ou as tentativas de profissionalização do sociólogo contribuíram, certamente, para uma maior representatividade da disciplina, seja no meio acadêmico superior, seja na escola secundária. No que diz respeito a esta última, existe também uma longa história, praticamente paralela à própria formação da sociologia, na França ou no Brasil, como será visto aqui de forma panorâmica.

Uma das primeiras diferenças estabelecidas entre o processo de introdução da sociologia no Ensino Médio, no caso da França e do Brasil, é o próprio fato da obrigatoriedade. Na França, a introdução da sociologia na escola secundária, nos programas do liceu, data de 1967 . No Brasil, apesar das várias tentativas ao longo da historia da disciplina, somente em 2008 a sociologia se oficializou obrigatoriamente no currículo da educação básica. Porém, enquanto no Brasil fala-se de sociologia, indicando de alguma forma uma autonomia da sociologia frente às outras ciências e disciplinas (economia, história, ciência política), na França o termo sociologia está embutido na expressão Sciences Économiques et Sociales (SES). Sua introdução na escola secundária está vinculada ao contexto das transformações econômicas pelas quais passa, não somente a França, mas também a Europa. Segundo Chatel et al. (1993, s.p.), 
[...] criada nos anos sessenta, em pleno período de crescimento econômico, o ensino das ciências econômicas e sociais nos liceus respondia a uma vontade de modernização da Escola e da sua abertura ao mundo contemporâneo. Um ensino novo, uma disciplina nova, as SES asseguram uma parte determinante da formação econômica e social dos jovens franceses ${ }^{6}$.

O sociólogo e economista francês Nicolas Postel (2009) esboça três objetivos do ensino das ciências econômicas e sociais: 1) elaborar representações teóricas prudentes, sobre a base de generalizações ou de hipóteses simplificadoras assumidas e dominadas; 2) renunciar a uma teoria pura, geral e a-histórica do social, à maneira de Walras (que fascina hoje as teorias liberais, apesar do fracasso de suas teorias); 3) recusar o dogma da impossibilidade de teorização que habitava nos anos 1930 uma parte dos institucionalistas (que concerne hoje aos historiadores, gestores ou sociólogos). Segundo Postel, esses princípios decorrem de três posturas: uma ontológica, recusando o naturalismo na ciência social; a epistemológica, que reivindica a unidade do social; e, finalmente, a postura metodológica, recusando a oposição da teoria abstrata e o empírico concreto.

Esses princípios constitutivos do projeto inicial das ciências econômicas e sociais estão no centro do debate ao longo do processo de constituição e consolidação, ou definição da função social da própria disciplina. Na atualidade, face às reformas propostas pelo governo francês, fixando uma prioridade à juventude e se concentrando amplamente sobre a refundação da escola, novas interrogações surgem a respeito da finalidade da instituição escolar. Nesse cenário, correspondente ao próprio projeto da educação, de assegurar aos jovens o direito de acesso a uma cultura geral e de exercer sua cidadania, consoante aos valores republicanos, desde os tempos durkheimianos, surge o debate sobre o lugar social das ciências econômicas e sociais, e do ensino da sociologia no interior dessa disciplina, uma vez que esta participa efetivamente de tais objetivos.

O debate sobre a reforma do ensino secundário afeta diretamente as ciências econômicas e sociais, não somente no que diz respeito ao conteúdo do ensino, quanto à sua carga horária. Assim, a proposta do Ministério de Educação consiste, além da redução da carga horária de três horas para uma hora e 30 minutos por semana para as ciências econômicas e sociais, uma mudança no programa da disciplina suprime todos os aspectos da realidade social. Trata-se, segundo Beaud (2010), de impor uma visão redutível e truncada do mundo real no qual vivemos. Ou seja, uma percepção desencarnada do mundo social. Sobretudo, deixa-se de falar de desemprego, desigualdade social e econômica, segregação social e urbana etc. Com a supressão da vertente ciências sociais, o governo francês prossegue seu objetivo, puramente ideológico, que é o de suprimir uma reflexão na escola secundária, na perspectiva

Educação \& Realidade, Porto Alegre, v. 39, n. 1, p. 59-80, jan./mar. 2014. 
O Ensino de Sociologia como Problema Epistemológico e Sociológico

das ciências econômicas e sociais. Isso significa eliminar uma concepção das ciências econômicas e sociais que visava, desde sua introdução nos liceus (como revelam os princípios supracitados), a apreender os fenômenos econômicos no seu encastramento social e sua historicidade, como pensava Karl Polanyi.

O objetivo parece bem definido: substituir uma ciência que contribui para pensar o mundo social numa perspectiva crítica, mas que continua marcada pelos acontecimentos de maio de 68 (quando a sociologia foi vista como esquerdista) por uma ciência econômica abstrata e fortemente formalizada. Entretanto sobre essa questão existem controvérsias entre os profissionais das ciências econômicas e sociais, como observa Chatel (2002, p. 138):

Quando os professores de Sciences Économiques et Sociales em 1980 dizem que lutam "pelo adjetivo social", eles contribuem para manter no ensino escolar um único ensino que pretende iniciar à sociologia. Mas não está garantido que eles tenham um projeto unânime de promoção pelo ensino da sociologia. Por conseguinte, a aliança de diversas ciências no interior das ciências econômicas e sociais torna-se mais claramente uma aliança entre economia-sociologia para o estudo de algumas grandes questões econômicas e sociais da atualidade. Esse posicionamento instala duravelmente a disciplina escolar num território específico, preservando-a da concorrência com as disciplinas vizinhas, como a história-geografia de um lado, economia-direito em ciências e tecnologias terciárias, até mesmo técnicas dos liceus, do outro. A agrégation em ciências econômicas e sociais contribuiu para que a disciplina ganhasse uma visibilidade e certa solidariedade dentro do sistema escolar, uma vez que o ensino dessa disciplina desfruta de um grande interesse dos alunos. No entanto, a evolução dessa disciplina não é julgada de forma unânime positiva pelos professores de ciências econômicas e sociais. Alguns veem como perda de identidade a economia de um lado e a sociologia de outro, e reclamam do academicismo e, uma tentação a renunciar o que deu significação profunda ao seu ensino, a saber, a educação de uma cidadania critica.

Esse debate, interno à profissão, no que diz respeito aos objetivos, à perspectiva epistemológica do ensino, do programa e sua articulação ao mundo social real, revela que, em matéria de ensino de ciências sociais do homem, não se escapa ao problema epistemológico, sociológico e político. O que está no centro da discussão, além da definição dos próprios objetivos da disciplina - quer dizer, de sua função social e do seu papel, não exclusivo, de contribuir para a articulação da formação do espírito crítico e os debates científicos - são as disputas pelo direito de falar com autoridade do mundo social. Para o caso na França, podemos pensar na antiga questão de definir o lugar do ensino das ciências 
econômicas e sociais no sistema escolar, através da questão colocada entre o savoirs savants e savoirs enseignés, que está no centro do que foi chamado de transposição didática.

\section{Dois Princípios Epistemológicos}

Nas lutas pela institucionalização da sociologia como disciplina obrigatória, tornou-se quase um lugar comum pensar a sociologia como a disciplina cujos objetivos são "educar para a cidadania" e, por extensão, "preparar para a inserção no mercado de trabalho" e "ensinar valores". Na França e no Brasil, parece que a escolha do programa dos saberes a serem ensinados, dentro do programa estabelecido, depende das considerações científicas, as quais Nicole Pinet chama de "lógica científica", que, nesse caso, se impõe, mas não sem divisão. Para esta autora (Pinet, 1999, p. 16),

[...] uma das lógicas manifestas nas ciências econômicas e sociais é qualificada de normativa. Os conteúdos do ensino não são somente determinados em função do seu interesse científico, mas também em referência aos valores, a ideais educativos. No que concerne às ciências econômicas e sociais, desde sua introdução no ensino secundário, era claramente anunciada sua ambição de contribuir para a formação do cidadão. O ideal de uma cidadania ativa orientou a definição dos programas, levando a privilegiar as questões que permitem, particularmente aos alunos, de compreender a sociedade na qual vivem, de participar com conhecimento de causa no seu funcionamento e nas suas transformações.

Podemos postular que os objetivos da educação em geral e da sociologia no nível médio em particular dependem, em certo sentido, das posições tomadas pelos agentes da educação, e no caso dos professores de sociologia, ou da instituição escolar como um todo, no campo das teorias pedagógicas e das próprias condições objetivas de trabalhos que as instituições oferecem. Para o propósito deste texto, cabe relembrar que, depois de tantas discussões de sociólogos inseridos na campanha nacional pela volta da sociologia à escola,

[...] as Orientações Curriculares Nacionais do Ensino Médio-OCNEM, de 2006 -, demarcam que o ensino de sociologia é disciplinar e tem dois eixos principais em termos de categorias-chave de ciência de referência: o estranhamento e a desnaturalização. Os alunos precisam aprender sociologia para desenvolverem uma postura intelectual autônoma diante dos fenômenos sociais em geral (Silva, 2009, p. 71) ${ }^{7}$.

Esses eixos que chamamos aqui de princípios epistemológicos são importantes não só para superar os chavões do senso comum, a respeito dos objetivos da sociologia, mas a fim de recuperar as posturas 
O Ensino de Sociologia como Problema Epistemológico e Sociológico

epistemológicas da própria ciência em geral, e da sociologia em particular. O estranhamento, aquela postura presente já na filosofia clássica, originalmente do grego Taumatos, significa admiração, espanto, a primeira condição para se colocar a questão inicial: por quê? O que faz isso ser assim e não de outra forma? Essa postura suscita explicação, e a busca da explicação possibilita consequentemente a desnaturalização do mundo e das coisas. Esses dois princípios caracterizam a sociologia como ciência compreensiva e explicativa, que é a perspectiva da própria sociologia clássica e refundada por um autor como Bourdieu. Como relembra L. Wacquant (2002, p. 100):

Bourdieu concebia a ciência social unificada [...] cuja missão é "desnaturalizar" e "desfatalizar" o mundo social, e "requerer condutas" por meios da descoberta das causas objetivas e das razões subjetivas que fazem as pessoas fazerem o que fazem; serem o que são, e sentirem da maneira que sentem. E dar-lhes, portanto, instrumentos para comandarem o inconsciente social que governa seus pensamentos e limita suas ações, como ele incansavelmente tentava fazer consigo mesmo.

Dito de outra forma, “[...] para Bourdieu, a tarefa da sociologia é de destruir os mitos, os fantasmas que habitam o exercício do poder e perpetuam a dominação”. O paradoxo, se podemos assim dizer, é que tanto o sociólogo quanto o leitor de suas análises habitam o mundo social. E à maneira kantiana, Bourdieu relembra que "o leitor lê a sociologia com as lentes do seu habitus" (1984, p. 41), que são matrizes de percepção do mundo social, construídas histórica e socialmente e pertencentes a um universo comum. De fato, esse habitus seria um habitus de classe.

Por essa razão, a luta da sociologia e dos sociólogos para romper com a sociologia espontânea é constante e diária.

\section{Institucionalização da Sociologia no Brasil: alguns elementos}

Como aludido desde a introdução, o estudo sobre o processo de institucionalização da sociologia no nível médio nos leva a rediscutir o processo de formação da sociologia no Brasil. Revisitando a literatura da história das ciências sociais no país, é possível verificar que, como na França, há uma tentativa de introdução da disciplina na escola secundária, que é paralela ao processo da própria formação da sociologia como ciência e sua institucionalização como disciplina no meio acadêmico, seja no nível superior, seja no nível secundário. Esboçar uma periodização parece útil para a compreensão do processo, porém as diferenciações nas datas estabelecidas são inevitáveis, segundo os critérios adotados para determinar quando se dá tal reconhecimento institucional e social da sociologia no Brasil. Como atesta Moraes (2011, p. 361):

As cronologias encerram certo paradoxo. Apresentam-se fundamentadas numa objetividade de datas que, no entan- 
to, estão marcadas pela escolha que o autor da cronologia exerce e, mais do que isso, ou por isso, tal escolha já éíndice de interpretação, ou seja, está sujeita a uma subjetividade.

Assim, se adotarmos uma perspectiva institucionalista, podemos demarcar o ano de 1930 como o momento em que os primeiros cursos universitários são criados em São Paulo, marco inicial para o surgimento das ciências sociais. Mas, a partir da perspectiva de Charles Wright Mills (1997), podemos dizer que uma "imaginação sociológica brasileira" pode ser observada desde o final do século XIX, quando o pensamento social era praticado por não especialistas.

Isso dito, podemos tomar a periodização estabelecida por Antônio Candido num texto clássico publicado em 1959, A Sociologia no Brasil (2006, p. 271-273). Nele, o autor distingue a formação da sociologia em três períodos: 1880-1930 e depois de 1940, intercalados por um curto período de transição (1930-1940), mas que é considerado como decisivo para os rumos das ciências sociais. No primeiro, a sociologia é praticada por intelectuais não especializados (juristas, médicos e engenheiros) interessados em formular princípios teóricos ou em interpretar de modo global a sociedade brasileira.

É justo, ainda, observar que esse pensamento social da época é marcado por um discurso literário e político. De Silvio Romero (autor de História da Literatura Brasileira, que procura explicar a gênese e evolução da literatura brasileira utilizando categorias geográficas, raciais e culturais) a Euclides da Cunha (que em seu clássico Os Sertões busca explicar as causas da Guerra de Canudos, um confronto entre os sertanejos e as forças da ordem republicana no Sertão da Bahia), pode-se encontrar uma tentativa de interpretar e sistematizar a realidade social brasileira, com o objetivo de se desenvolver uma teoria geral do Brasil (Candido, 2006). As características desse período, que marca a imaginação sociológica, são as categorias da geografia, raciais e estruturais que, segundo os estudiosos da época, produziram o país tal qual era conhecido (Maia; Pereira, 2009). Outrossim, o positivismo de Auguste Comte teve um lugar importante no pensamento social da época, especialmente entre os militares e os homens de ciência. O darwinismo social também exerceu grande influência sobre a elite intelectual brasileira, que buscava explicações sobre a evolução da sociedade, bem como o lugar do país no contexto global. Todavia, nesse período, não se registra o seu ensino nem a pesquisa empírica sobre aspectos delimitados da realidade.

O segundo período (1930-1940), apesar de sua curta duração, é o mais importante, porque é o momento em que a sociologia começa a aparecer no ensino superior e secundário. Assim, para Sérgio Miceli (s.d.), é possível determinar o início da institucionalização do ensino das ciências sociais no Brasil desde 1930, com o estabelecimento de diversas instituições de ensino e pesquisa. De acordo com este autor,

Educação \& Realidade, Porto Alegre, v. 39, n. 1, p. 59-80, jan./mar. 2014.

Disponível em: <http://www.ufrgs.br/edu_realidade> 
[...] o desenvolvimento institucional e intelectual das ciências sociais no Brasil esteve estreitamente associado, de um lado, ao impulso alcançado pela organização universitária e, de outro, à concessão de recursos governamentais para a montagem de centros de debate e investigação que não estavam sujeitos à chancela do ensino superior (Miceli, s.d., s.p.).

Podemos dar alguns exemplos dos mais significativos: em 1935, foi criada a Universidade do Distrito Federal, sob a liderança de Pedro Ernesto, então prefeito do Rio de Janeiro, a capital do país na época. Renomados pesquisadores foram recrutados, entre os quais estavam Josué de Castro (autor de Geografia da Fome), Gilberto Freyre (autor de Casa Grande e Senzala) e Arthur Ramos. Esse projeto sofreu uma intervenção federal, que via em Pedro Ernesto um adversário político. Em seguida, essa instituição se associou ao Estado Novo e ao seu projeto autoritário, e foi dirigida por grupos católicos que se opuseram ao projeto inicial da Universidade do Distrito Federal.

De acordo com Maia e Pereira (2009), as ciências sociais no Rio de Janeiro foram caracterizadas pela difusão de raciocínio sociológico não em universidades consagradas à pesquisa científica, mas em instituições públicas. Esse é o caso do Instituto Brasileiro de Geografia e Estatística (IBGE), criado em 1938, e do Instituto Nacional de Estudos Pedagógicos (Inep). Essa ambiguidade entre ciência e política tornouse evidente com a fundação, em 1952, do Instituto Superior de Estudos Brasileiros (Iseb), uma espécie de agência intelectual de apoio para o desenvolvimento nacional. Nessa instituição, controlada pelo Ministério da Educação, estiveram associados intelectuais como Hélio Jaguaribe, Guerreiro Ramos, Nelson Werneck Sodré, entre outros (Maia; Pereira, 2009).

No entanto o marco entre as instituições acadêmicas que simboliza a institucionalização das ciências sociais no Brasil e que abriu uma nova perspectiva para a formação do pensamento sociológico é, notadamente, a fundação da Faculdade de Filosofia, Ciências e Letras da Universidade São Paulo, em 1934. A faculdade foi fundada por iniciativa da elite de São Paulo, como estratégia para a reconstrução e a reestruturação do poder perdido durante a Revolução de 1930. Para esse fim, intelectuais franceses vieram com a missão de fortalecer as humanidades na universidade: Claude Lévi-Strauss, Fernand Braudel, François Peroux, Roger Bastide, para citar apenas estes. Para Miceli (s.d.), a sociologia praticada a partir desse período seria mais independente academicamente do que a praticada no Rio de Janeiro, e a produção intelectual teria uma envergadura mais próxima dos grandes centros de pesquisa científica, por seu rigor teórico e metodológico.

A partir dos anos 1940 se deu a consolidação e a generalização da sociologia como disciplina e atividade de pesquisa socialmente reconhecida, como produção regular no campo teórico, da pesquisa e apli- 
cação. É importante notar que, se as tentativas de institucionalização da sociologia na França e no Brasil são paralelas, no país de Durkheim, por condições próprias da fundação do conhecimento sociológico, tal consolidação enquanto ciência se deu mais cedo do que no Brasil.

Nesse período, os principais representantes daquela que ficou conhecida como Escola Sociológica Paulista foram: Florestan Fernandes, Otávio Ianni, Fernando Henrique Cardoso. Florestan Fernandes foi um dos mais influentes da nova geração de sociólogos e, em grande parte, um dos responsáveis pela institucionalização da sociologia científica no Brasil e um dos principais difusores de sociologia durkheimiana e do marxismo na Universidade de São Paulo.

De acordo com alguns analistas, houve uma forte tensão entre a Escola Sociológica no Rio de Janeiro (Iseb), liderada por Guerreiro Ramos, e a Escola de Sociologia de São Paulo, sob a direção de Florestan Fernandes. Essa controvérsia consistia no fato de que Guerreiro Ramos defendia que a sociologia praticada em países subdesenvolvidos devia utilizar os escassos recursos econômicos em projetos para compreender o desenvolvimento nacional, enquanto que Florestan Fernandes argumentava que os sociólogos brasileiros deviam continuar com a consciência teórica e o mesmo rigor científico dos países centrais. Assim, os sociólogos da escola de São Paulo trabalhavam para o estabelecimento de um conhecimento sociológico baseado em um método científico rigoroso, a fim de romper com o ensaísmo herdado do final do século XIX (Maia; Pereira, 2009).

Assim, a consolidação das ciências sociais não ocorreu apenas com as instituições de ensino, mas também com as instituições de pesquisa, como já elucidado no caso francês.

\section{A Sociologia no Ensino Médio: uma história intermitente}

Sobre a história do ensino de sociologia no nível médio, os sociólogos comprometidos com sua introdução em seu caráter obrigatório e a consolidação de seu ensino vêm mobilizando seus conhecimentos e pesquisas científicas para a elaboração de uma sociologia histórica da disciplina no Brasil, cujo lugar ocupado no ensino se caracteriza de forma intermitente. Essa literatura em formação propõe uma leitura analítica do processo, o qual desvela as lutas políticas e ideológicas que estão por trás das resistências à sociologia na formação educacional brasileira.

No intuito de esboçar uma periodização, podem-se citar alguns fatos que marcaram a história da disciplina: as primeiras tentativas aparecem logo depois da Proclamação da República, com a reforma da educação sob a égide da Benjamin Constant, ministro de Floriano Peixoto, que defendia o ensino laico em todos os níveis, cujo objetivo era proporcionar a formação intelectual dos jovens não mais sob os auspícios da Igreja Católica (a exemplo do que se passou na França, na III

Educação \& Realidade, Porto Alegre, v. 39, n. 1, p. 59-80, jan./mar. 2014. 75 
O Ensino de Sociologia como Problema Epistemológico e Sociológico

República). No entanto esse projeto não foi bem-sucedido e, em 1901, numa nova reforma da educação conduzida por Epitácio Pessoa, a sociologia foi retirada do currículo. Foi preciso esperar até 1925 para que, com a reforma Rocha Vaz, a disciplina fosse introduzida como obrigatória em programa de formação no ensino secundário. Os conteúdos eram vistos como necessários para ingressar nos exames universitários.

O ano de 1931 é outra data importante. Nesse ano, o ministro da Educação Francisco Campos organizou o ensino secundário em dois ciclos: o ciclo fundamental de cinco anos e um ciclo complementar dividido em três opções como preparação para o ingresso às faculdades de Direito, Medicina, Engenharia e Arquitetura e, por isso, chamado de curso preparatório. Contudo, durante os anos de 1942 a 1961, com a Reforma Capanema, a sociologia não somente perdeu seu caráter obrigatório, mas foi novamente excluída dos programas escolares. A partir daí, com a chegada ao poder de um governo militar, a disciplina desapareceu do programa e foi estigmatizada, assim como a filosofia, como uma disciplina subversiva que colocaria em risco a ordem estabelecida, confundida com o socialismo e o comunismo.

Malgrado os projetos iniciais, desde a Proclamação da Republica, foi somente em 1996 que a luta pela introdução da sociologia na educação básica se tornou mais evidente, e sua institucionalização se consolidou tão somente com a aprovação de leis no âmbito do governo federal. Em 1996 a nova LDB, Lei 9.394/96, no seu art. 36, parágrafo $1^{\circ}$, inciso III, estabelece que, "[...] ao final do ensino médio o educando demonstre: domínio de conhecimentos de filosofia e sociologia necessários ao exercício da cidadania”. Em 1998, foram publicadas as Diretrizes Curriculares Nacionais do Ensino Médio (DCNEM), regulamentadas pela Resolução CNE/CEB3/98, que dava a seguinte interpretação: “[...] as propostas pedagógicas das escolas deverão assegurar tratamento interdisciplinar e contextualizado para o conhecimento de filosofia e sociologia necessário ao exercício da cidadania" (Moraes, 2003, p. 8). Paralelamente a isso, o governo federal publicou os Parâmetros Curriculares Nacionais (PCN) para o Ensino Médio, incluindo o PCN/Sociologia na área de conhecimento Ciências Humanas e suas Tecnologias (PCN, Nível Médio, 1999). Nos anos 2000, tramitou no Congresso Nacional um projeto de Lei (PL $\left.{ }^{\circ} 09 / 00\right)$ que visava a alterar o art. 36, parágrafo $1^{\circ}$, inciso III da Lei $\mathrm{n}^{\circ} 9.394$, afirmando a obrigatoriedade das disciplinas sociologia e filosofia no Ensino Médio.

Esse breve esboço é suficiente para se perceber o longo processo e as lutas travadas pelos sociólogos para fazer valer o reconhecimento social de sua disciplina, reconhecimento esse em constante luta por afirmação. Cabe ainda ressaltar, entretanto, que o problema da falta de legitimidade da disciplina no interior da escola média e de universidades que formam os futuros profissionais e professores leva em conta, além do problema da institucionalização da disciplina do ponto de vista jurídico ou científico, as relações de força no interior do espaço acadêmico 
e científico. Desse modo, a partir de análises e observações feitas por professores com experiência no ensino, pesquisadores e estudantes em universidades brasileiras nos últimos anos, tanto nos grandes centros urbanos como em outras regiões, parece legítimo afirmar a existência de obstáculos bastante comuns quanto à consolidação de seu ensino. Esses obstáculos são muitos e, aqui, cabe apenas indicar brevemente seu caráter: vão da tradicional dicotomia entre pesquisa e ensino à falta de material didático adequado ao nível de ensino e contextualizado nas situações social, econômica e cultural de nossas regiões, passando pela falta de professores formados em ciências sociais. Desses obstáculos, elege-se a querela entre bacharelado e licenciatura, que parece mais complexa e urgente a ser superada, para algumas considerações. Estima-se que a separação entre pesquisa e ensino leva a um debate infrutífero e que aparece, segundo Moraes (2009, p. 20),

Como decorrente da imprecisão de que os professores são mal formados, o que causava e causa ainda certa resistência quanto a aceitar a obrigatoriedade do ensino da sociologia no nível médio. O problema todo é fazer algumas passagens, algumas mudanças de ponto de vista: a primeira é que a formação do bacharel não é suficiente, embora necessária, para garantir ao professor condições para o exercício das atividades de ensino; a segunda é que se pode pensar a licenciatura, e não exclusivamente o bacharelado, também como um espaço de pesquisa. Isso, no entanto, importa numa revisão do currículo dos cursos de ciências sociais e na busca de equilíbrio entre o bacharelado e licenciatura (Moraes, 2009, p. 20).

Uma questão pouco discutida, e muitas vezes camuflada, é a relação de força que está por trás dessa oposição entre as duas fileiras acadêmicas em ciências sociais: pesquisa e ensino. Os pesquisadores bacharéis em Ciências Sociais, que possuem grupos de pesquisas institucionalizados e pesquisas em andamento, conseguem, mais facilmente, financiamentos para suas pesquisas e têm mais chances de ocupar posição dominante no interior dos departamentos, notadamente nos programas de pós-graduação nos níveis de mestrado e doutorado - o que lhes permite, por consequência, a aquisição de bolsas das instituições de fomento (Capes, CNPq etc.). Através dessas instituições, por exemplo, pelo Programa Institucional de Bolsa de Iniciação Científica (Pibic), recrutam precocemente estudantes da graduação na modalidade bacharelado para participar de projetos de pesquisas, o que permite a estes últimos, se iniciarem e se apropriarem das técnicas de pesquisa em ciências sociais. Esse enquadramento institucional dos estudantes não somente lhes propicia a aquisição de saberes científicos e de savoirfaire, mas também lhes permite aceder mais facilmente aos níveis de mestrado e doutorado e de construírem sua trajetória acadêmica de alto nível. Isso funciona como estratégia de produção e reprodução social do corpo docente da instituição de ensino superior. 
Em contrapartida, os estudantes inscritos na modalidade licenciatura, cujo programa acentua a formação de professores, têm mais dificuldades de se engajarem na pesquisa e almejar um futuro acadêmico de nível superior, mesmo que, do ponto de vista do conteúdo programático, a formação dessas duas modalidades seja praticamente a mesma, com eixos comuns em antropologia, sociologia e ciência política. Frequentemente, a diferença específica entre as duas fileiras nas universidades se encontra nas disciplinas ditas pedagógicas ou das teorias da educação (sociologia, filosofia e sociologia da educação).

Importa dizer que o Programa Institucional de Bolsa de Iniciação à Docência (Pibid), implementado em várias universidades no Brasil, tem oferecido uma grande contribuição para o desenvolvimento de uma mentalidade acadêmica voltada para a prática docente, mas, sobretudo, visando à superação da divisão arbitrária entre pesquisa e ensino e consolidar a ideia de que a escola deve ser tomada e pensada como um espaço de pesquisa e de extensão.

\section{Considerações Finais}

A partir do amplo debate realizado nestes últimos anos, é possível afirmar que o caráter intermitente da história da sociologia na escola média, não somente no Brasil, como na França, não está somente ligado às decisões políticas e ideológicas situadas no curso das transformações sociais e econômicas, mas também às lutas no interior do campo acadêmico e científico. Nesse sentido, o problema do ensino de sociologia no Ensino Médio não se explica mais somente pela falta de legitimidade, do ponto de vista legal, mas pela falta de reconhecimento social (função social) e do seu status de ciência. A história da sociologia é diferente das outras ciências e disciplinas, no sentido de que é uma ciência recente e, mais recente ainda, a história da disciplina. Desse modo, o processo de constituição de uma ciência difere do processo de constituição de uma disciplina, esta precedida por aquela. A preocupação com o estabelecimento da disciplina (teorias, conceitos e temas) surge da necessidade de sua transmissão, ou seja, enquanto estratégia de circulação dessa forma específica de conhecimento, com o objetivo de torná-la legítima e reconhecida no espaço de possíveis do campo científico, segundo expressão de Pierre Bourdieu. No entanto são processos históricos situados em lutas políticas que, na maioria das vezes, têm a ver com os rumos que tomam as sociedades e os governos.

Recebido em 06 de março de 2013 Aprovado em 07 de junho de 2013

\section{Notas}

1 As traduções são livres do autor, exceto quando indicado.

2 Tradução de Inês Duarte Ferreira. 
3 Sobre essa questão, ver Hervé Serry (2004).

4 Para mais informação a esse respeito, ver Émile Durkheim (2008).

5 Revista fundada por Louis Joseph Lebret, intitulada Économie et Humanisme.

6 O sociólogo francês Sthéphane Beaud (2012) relembra que a introdução da sociologia, no ensino secundário e em classe preparatória, serve como uma espécie de recrutamento escolar. Os jovens sociólogos formados entre os anos 1990 e 2010 se caracterizam pelo mesmo dualismo de recrutamento dos seus predecessores, sem dúvida, reforçado pela grande difusão do ensino da sociologia, primeiro, no ensino secundário (ciências econômicas e sociais), depois, externamente à universidade, notadamente nas classes preparatórias (criação de khâgne em 1983) e nos estudos de ciência política (Paris, Bordeaux, Lille, Lyon, Strasbourg, Toulouse).

7 É importante lembrar, é claro, que isso não é somente uma tarefa da sociologia. No entanto é justo enfatizar o caráter específico dessa ciência.

8 Para informações mais detalhadas sobre as idas e voltas da sociologia na educação básica, ver Moraes (2003) e Carvalho (2004).

\section{Referências}

BEAUD, Sthépane. Lycée: éco sans socio n'est que ruine de l'âme. Le Libération, Paris, 8 fev. 2010.

BEAUD, Sthépane. La Sociologie Française au Milieu du Gué. SociologieS, Débats, La situation actuelle de la sociologie, 27 jan. 2012. Disponível em: <http:// sociologies.revues.org/3880>. Acesso em: 10 out. 2012.

BOURDIEU, Pierre. Questions de Sociologie. Paris: Éditions de Minuit, 1984.

CANDIDO, Antônio. Sociologia no Brasil (1959). Tempo Social, São Paulo, v. 18, n. 1, p. 271-301, jun. 2006.

CARVALHO, Lejeune Mato Grosso de. A Trajetória Histórica da Luta Pela Introdução da Disciplina de Sociologia no Ensino Médio no Brasil. In: CARVALHO, Lejeune Mato Grosso de (Org.). Sociologia e Ensino em Debate: experiência de discussão de sociologia no Ensino Médio. Ijuí: Editora Unijuí, 2004. P. 17-60.

CHATEL, Elisabeth; GROSSE, Gérard. L'Enseignement Sociologique au Lycée: entre problèmes sociaux et sociologie savante. Education et Sociétés, n. 9, 2002. CHATEL, Elisabeth et al. Enseigner les Sciences Économiques et Sociales: le projet et son histoire. INRP, 1993. Disponível em: <http://ses.ens-Ish.fr/pdf/ses/ chatel.pdf>. Acesso em: 23 set. 2012.

CHENU, Alain. Une Institution Sans Intention: la sociologie en France depuis l'après-guerre. Actes de la Recherches en Sciences Sociales, Paris, n. 141-142, p. 46-61, 2002.

DUBAR, Claude. Les Tentatives de Professionalisation de la Sociologie. In: LAHIRE, Bernard (Org.). A Quoi Sert la Sociologie? Paris: La Découverte, 2002. P. 95-117.

DUBET, François. Dites-nous, François Dubet, à quoi sert vraiment la sociologie? Paris: Armand Colin, 2011.

DURKHEIM, Émile. A Ciência Social e a Ação. Lisboa: Livraria Bertrand, 1973.

DURKHEIM, Émile. A Educação Moral. Petrópolis: Vozes, 2008.

Educação \& Realidade, Porto Alegre, v. 39, n. 1, p. 59-80, jan./mar. 2014.

Disponível em: <http://www.ufrgs.br/edu_realidade> 
O Ensino de Sociologia como Problema Epistemológico e Sociológico

HEILBRON, John. La Professionalisation Comme Concept Sociologique et Comme Stratégie des Sociologies. In: SOCIETÉ FRANÇAISE DE SOCIOLOGIE. Historiens et Sociologues Aujourd'hui: journées d'études annueles. Paris: CNRS, 1986. P. 61-73.

LAHIRE, Bernard. Introduction. . In: LAHIRE, Bernard (Org.). A Quoi Sert la Sociologie? Paris: La Découverte, 2002. P. 5-12.

MAIA, João Marcelo Ehlert; PEREIRA, Luiz Fernando Almeida. Pensando com a Sociologia. Rio de Janeiro: FGV, 2009.

MICELI, Sérgio. Condicionantes do desenvolvimento das Ciências Sociais no Brasil (1930-1964). [s.d.]. Disponível em: <http://www.anpocs.org.br/portal/publicacoes/rbcs_00_05/rbcs05_01.htm>. Acesso em: 9 maio 2012.

MORAES, Amaury César. Licenciatura em Ciências Sociais e Ensino de Sociologia: entre o balanço e o relato. Tempo Social, São Paulo, v. 15, n. 1, p. 5-20, abr. 2003.

MORAES, Amaury César. Desafios para a Implantação do Ensino da Sociologia na Escola Média Brasileira. In: HANDFAS, Anita; OLIVEIRA, Luiz Fernandes de (Org.). A Sociologia Vai à Escola: história, ensino e docência. Rio de Janeiro: Quartet/FAPERJ, 2009. P. 19-29.

MORAES, Amaury Cesar. Ensino de Sociologia: periodização e campanha pela obrigatoriedade. Cadernos CEDES, Campinas, Universidade Estadual de Campinas, v. 31, p. 359-382, 2011.

PINET, Nicole. De la Sociologie aux Sciences Économiques et Sociales. DEES, n. 115, mar. 1999.

POSTEL, Nicolas. Editorial: L'Enseignement des SES et L'unité des Sciences Sociales. Revue Française de Socio-Économie, Lille, n. 3, p. 5-9, 2009.

SERRY, Hervé. Saint-Thomas Sociologue? Les enjeux cléricaux d'une sociologie catholique. Actes de la Recherches en Sciences Sociales, Paris, n. 153, p. 28-39, jun. 2004.

SILVA, Ileizi Luciana Fiorelli. Fundamentos e Metodologias do Ensino de Sociologia na Educação Básica. In: HANDFAS, Anita; OLIVEIRA, Luiz Fernandes de (Org.). A Sociologia Vai à Escola: história, ensino e docência. Rio de Janeiro: Quartet/FAPERJ, 2009. P. 64-91.

WACQUANT, Loïc. O Legado Sociológico de Pierre Bourdieu: duas dimensões e uma nota pessoal. Revista de Sociologia Política, Curitiba, n. 19, p. 95-110, nov. 2002.

WRIGHT MILLS, Charles. L'Imagination Sociologique. Paris: La Découverte, 1997.

Juarez Lopes de Carvalho Filho é doutor e mestre em Sciences Sociales et Économiques pela Universitas Catholica Parisiensis (França), graduado em Filosofia pela Universidade Estadual do Ceará e Mestre em Filosofia pela Université Paris VIII. É professor e pesquisador do Departamento de Sociologia e Antropologia da Universidade Federal do Maranhão (UFMA). Desenvolve pesquisas em Teoria Sociológica e Sociologia da Educação e da Cultura.

E-mail: juarez.lopes@gmail.com 